\title{
Microspherophakia in a 47, XYY Syndrome Patient: A Case Report
}

\author{
Maria Lourdes Rubalcava-Soberanis ${ }^{a} \quad$ Bani Antonio-Aguirre ${ }^{a, b}$ \\ Cristina Mendoza Velásquez ${ }^{a} \quad$ Andric Christopher Perez-Ortiz ${ }^{c, d}$ \\ Claudia Palacio-Pastrana ${ }^{a}$ \\ aDepartment of Microsurgery of the Anterior Segment, Fundación Hospital Nuestra \\ Señora de la Luz IAP, Mexico City, Mexico; bepartment of Molecular Biology and \\ Biochemistry, Universidad Panamericana Escuela de Medicina, Mexico City, Mexico; \\ 'Department of Public Health, Universidad Panamericana Escuela de Medicina, Mexico \\ City, Mexico; dDepartment of Surgery, Massachusetts General Hospital, Boston, MA, USA
}

\section{Keywords}

47, XYY syndrome $\cdot$ Microspherophakia $\cdot$ Phacomorphic glaucoma $\cdot$ Rare diseases

\begin{abstract}
47, XYY syndrome affects males with variable phenotypic expression. Around $80-99 \%$ of affected individuals present low-set ears, malar flattening, motor delay, and tall stature. Yet, some cases lack signs or symptoms or are barely noticeable. There are four reports of ocular involvement among these individuals - one with unusual multiple retinal atrophic holes in the posterior pole, other with coloboma, an association with morning glory syndrome, and a case of congenital cataract. Here, we describe a plausible new ocular sign in a 4-year-old male with $47, \mathrm{XYY}$ syndrome who was brought to the outpatient clinic for vision loss. After a complete assessment, we diagnosed a right-sided phacomorphic glaucoma and microspherophakia treated with phacoemulsification and aspiration with posterior capsulotomy and anterior vitrectomy, followed by an Ahmed valve implant for intraocular pressure control. Even though there is a low prevalence of ocular involvement in $47, \mathrm{XYY}$ syndrome cases, this might reflect
\end{abstract}

Fundación Hospital Nuestra Señora de la Luz, IAP

Ezequiel Montes \#135, Col. Tabacalera, Mexico City 06030 (Mexico)

E-Mail cpalaciopastrana@gmail.com 
Case Reports in
Ophthalmology

Case Rep Ophthalmol 2020;11:1-7

DOI: 10.1159/000505058

(c) 2020 The Author(s). Published by S. Karger AG, Basel www.karger.com/cop

Rubalcava-Soberanis et al.: Microspherophakia in a 47, XYY Syndrome Patient: A Case Report

the rarity of the full expression of the disease leading to an underdiagnosis, added to the scarcity of cases. Microspherophakia and phacomorphic glaucoma among four others previously reported ocular findings could be looked for in 47, XYY syndrome patients.

(C) 2020 The Author(s)

Published by S. Karger AG, Basel

\section{Introduction}

The $47, \mathrm{XYY}$ syndrome is a rare trisomy affecting 1 in 1,000 newborn males. The most common etiology stems from a parental nondisjunction of the $\mathrm{Y}$ chromosome at meiosis II, resulting in a 47, XYY karyotype [1]. Affected cases have variable expression (broad phenotypic spectrum), ranging from unperceivable features to developmental alterations [2]. The most prevalent findings among affected cases are low-set ears, malar flattening, clinodactyly, hypertelorism, and tall stature. Asthma is also present in 30-79\% of cases [3, 4]. Usually, cognitive function is normal. However, motor retardation, delay in speech development, attention deficit and hyperactivity disorder, autism, hypotonia, and, more typically, extreme aggressiveness could also occur $[5,6]$. Most men with 47, XYY syndrome have normal spermatogenesis and produce chromosomally normal children; but in a small proportion, present oligozoospermia [6-8].

Few reports have assessed the craniofacial development of males with the karyotype XYY. However, there is evidence to suggest that affected cases course with abnormal growth of these structures since birth $[9,10]$. It is rare for chromosomally normal children to undergo anterior segment alterations or retinal alterations other than congenital cataracts or retinoblastoma [11-13]. Among 47, XYY cases, only 4 cases have reported specific ocular alterations in the retina and the anterior segment of the eye [14-17]. Here, we present a case with a plausible ophthalmological sign that may contribute to the comprehensive evaluation and follow-up of individuals with 47, XYY syndrome.

\section{Case Presentation}

A 4-year-old male was brought to the outpatient clinic complaining of vision loss. The mother noticed clumsiness, constant eye rubbing, head tilting and covering one eye, holding things close to his face, and occasional ocular pain. He was diagnosed at birth with 47, XYY syndrome by clinical findings and karyotyping. Other comorbidities were asthma diagnosed at 2 years, under control, the rest was unremarkable. There was no family history suggestive of any genetic diseases. On exam, macroscopically there were no conjunctival injection or epiphora; the ocular range of movements was normal. The pupils were round and reactive with normal reflexes. Right-eye refraction was $-6.00-1.00 \times 30^{\circ}$, and left-eye was $-5.00-1.50$ $\times 20^{\circ}$. We did not perform visual acuity and peripheral vision exams due to an underaged uncooperative patient. Under anesthesia, we observed a translucent right cornea with a horizontal diameter of $12.5 \mathrm{~mm}$, a well-formed narrow anterior chamber (depth $1.04 \mathrm{~mm}$ ), closed iridocorneal angle in $360^{\circ}$, round translucent crystallin protruding anteriorly, and intraocular pressure of $26 \mathrm{~mm} \mathrm{Hg}$ (Fig. 1, 2). Left eye examination evidenced a corneal horizontal 
Case Reports in
Ophthalmology

Case Rep Ophthalmol 2020;11:1-7

DOI: 10.1159/000505058

(c) 2020 The Author(s). Published by S. Karger AG, Basel www.karger.com/cop

Rubalcava-Soberanis et al.: Microspherophakia in a 47, XYY Syndrome Patient: A Case Report

diameter of $11.5 \mathrm{~mm}$ with an open iridocorneal angle in all four quadrants. Additionally, multiple iridian processes with a posterior embryotoxon in the temporal sector were present. The intraocular pressure on tonometry was $14 \mathrm{~mm} \mathrm{Hg}$. Fundoscopic examination revealed an excavated papilla of $90 \%$ OD and $40 \%$ OS with no other retinal or macular changes. Based on these findings, we diagnosed right microspherophakia with phacomorphic glaucoma. We performed phacoemulsification and aspiration of the lens with posterior capsulotomy and anterior vitrectomy. An intraocular lens (IOL) was implanted in the capsular bag. Despite a successful IOL position, the patient continued with increased right intraocular pressure postoperatively. Three weeks later, we decided to place an Ahmed valve implant for intraocular pressure control. During follow-up, the right intraocular pressure remained within normal limits. No additional intraocular pressure-lowering drugs were required as an adjuvant.

\section{Discussion}

To our knowledge, there are only four cases of ocular involvement among 47, XYY syndrome cases reported in the literature (Table 1). The rarity of the disease and full expression might be conducive to an underdiagnosis added to the scarcity of cases. In 2009, a case report of a 7-month-old male with 47, XYY syndrome described findings compatible with morning glory syndrome. An ophthalmologist assessed the patient for slowed pupillary reflexes, as well as an inability to track light. Fundoscopic examination revealed bilateral optic disc enlargement, with a thickened and pigmented choroid highly suggestive of morning glory syndrome [16]. On MRI, agenesis of the corpus callosum and lateral ventricle malformations confirmed the diagnosis. A second report suggested the association of the syndrome with the presence of iris and retina coloboma, as well as high myopia, as was the case in our patient [14]. Even though there was a diverse presentation among these cases, the fact that they presented ocular alterations at a young age, most of them before the age of 5 years, is highly indicative of its genetic association rather than it being sporadic.

Here, the patient presented with microspherophakia, a condition that results from abnormal development of the lens. A decreased equatorial diameter produces a spherical or globular shape. Typically, among these cases, it is possible to visualize the lens equator under mydriasis. The morphology is conducive to high myopia and increases the risk of producing a pupillary block, consequently leading to secondary angle closure glaucoma $[18,19]$. The primary and widely known associations of the microspherophakia are Weill-Marchesani syndrome, Peters anomaly, Lowe syndrome, and Alport syndrome [20-22]. In our case, we believe that the presentation could have been influenced by different genetic factors associated with his chromosomal condition. Taken together, microspherophakia is potentially a new ophthalmological clinical finding associated with 47, XYY syndrome cases. Our and other ocular findings should be considered when evaluating a similar case to provide precise and timely diagnosis, improving overall visual prognosis in these individuals. 


\section{Statement of Ethics}

Written informed consent was obtained from the parents (legal guardians) of the minor for publication of this report and any presented images.

\section{Disclosure Statement}

All of the authors declare a nonexistent conflict of interest regarding the publication of the present article.

\section{Funding Sources}

None.

\section{Author Contributions}

Conceptualization: Maria Lourdes Rubalcava-Soberanis, Claudia Palacio-Pastrana; data collection: Maria Lourdes Rubalcava-Soberanis, Claudia Palacio-Pastrana; analysis: Maria Lourdes Rubalcava-Soberanis, Bani Antonio-Aguirre, Andric Christopher Perez-Ortiz; writing - original draft preparation: Maria Lourdes Rubalcava-Soberanis, Bani Antonio-Aguirre, Andric Christopher Perez-Ortiz; writing - review and editing: Maria Lourdes RubalcavaSoberanis, Bani Antonio-Aguirre, Andric Christopher Perez-Ortiz, Claudia Palacio-Pastrana; supervision: Andric Christopher Perez-Ortiz, Claudia Palacio-Pastrana.

\section{References}

1 Robinson DO, Jacobs PA. The origin of the extra Y chromosome in males with a 47,XYY karyotype. Hum Mol Genet. 1999 Nov;8(12):2205-9.

2 Stochholm K, Juul S, Gravholt CH. Diagnosis and mortality in 47,XYY persons: a registry study. Orphanet ] Rare Dis. 2010 May;5(1):15-15.

3 Bardsley MZ, Kowal K, Levy C, Gosek A, Ayari N, Tartaglia N, et al. 47,XYY syndrome: clinical phenotype and timing of ascertainment. J Pediatr. 2013 Oct;163(4):1085-94.

4 Speicher M, Vogel F. Chromosomal Aneuploidies in Humans. Vogel and Motulsky's Human Genetics. Berlin: Springer; 2010. p. 125.

5 Ross JL, Roeltgen DP, Kushner H, Zinn AR, Reiss A, Bardsley MZ, et al. Behavioral and social phenotypes in boys with 47,XYY syndrome or 47,XXY Klinefelter syndrome. Pediatrics. 2012 Apr;129(4):769-78.

6 Leggett V, Jacobs P, Nation K, Scerif G, Bishop DV. Neurocognitive outcomes of individuals with a sex chromosome trisomy: XXX, XYY, or XXY: a systematic review. Dev Med Child Neurol. 2010 Feb;52(2):119-29.

7 Rives N, Milazzo JP, Miraux L, North MO, Sibert L, Mace B. From spermatocytes to spermatozoa in an infertile XYY male. Int J Androl. 2005;28(5):304-10.

8 Kim IW, Khadilkar AC, Ko EY, Sabanegh ES Jr. 47,XYY Syndrome and Male Infertility. Rev Urol. 2013;15(4):188-96.

9 Pentinpuro R, Pesonen P, Alvesalo L, Lähdesmäki R. Crown heights in the permanent teeth of 47,XYY males. Acta Odontol Scand. 2017 Jul;75(5):379-85. 


\section{Case Reports in Ophthalmology}

Case Rep Ophthalmol 2020;11:1-7

Rubalcava-Soberanis et al.: Microspherophakia in a 47, XYY Syndrome Patient: A Case Report

10 Lalatta F, Folliero E, Cavallari U, Di Segni M, Gentilin B, Fogliani R, et al. Early manifestations in a cohort of children prenatally diagnosed with 47,XYY. Role of multidisciplinary counseling for parental guidance and prevention of aggressive behavior. Ital J Pediatr. 2012 Oct;38(1):52.

11 Castillo BV Jr, Kaufman L. Pediatric tumors of the eye and orbit. Pediatr Clin North Am. 2003 Feb;50(1):14972.

12 Gilbert C, Foster A. Childhood blindness in the context of VISION 2020-the right to sight. Bull World Health Organ. 2001;79(3):227-32.

13 Foster A, Gilbert C, Rahi J. Epidemiology of cataract in childhood: a global perspective. J Cataract Refract Surg. 1997;23 Suppl 1:601-4.

14 Kitsiou S, Bartsocas CS. Unusual association of XYY chromosomal constitution with colobomas of iris, myopia, increased lipoproteins, mental retardation and convulsions. Ann Genet. 1986;29(4):264-5.

15 Kremer I, Feuerman PE, Yassur Y, Lusky M, Lapidot M. Unusual posterior retinal holes associated with high myopia in XYY syndrome. Ann Ophthalmol. 1990 Dec;22(12):450-3.

16 Chew FL, Visvaraja S. 47 XYY and morning glory syndrome-a unique association. J AAPOS. 2009 Aug;13(4):406-7.

17 Medina-Andrade A, Villanueva-Mendoza C, Arenas S, Cortés-González V. Cataract in a patient with 47,XYY sex chromosome aneuploidy. Arch Soc Esp Oftalmol. 2018 Jun;93(6):303-6.

18 Şimşek T, Beyazyıldız E, Şimşek E, Öztürk F. Isolated Microspherophakia Presenting with Angle-Closure Glaucoma. Turk J Ophthalmol. 2016 Oct;46(5):237-40.

19 Caglar C, Yasar T. Glaucoma caused by isolated microspherophakia: A long story. Indian J Ophthalmol. 2014 Nov;62(11):1106-1106.

20 Mete UÖ, Karaaslan C, Özbilgin MK, Polat S, Tap 0, Kaya M. Alport's syndrome with bilateral macular hole. Acta Ophthalmol Scand. 1996 Feb;74(1):77-80.

21 Guo H, Wu X, Cai K, Qiao Z. Weill-Marchesani syndrome with advanced glaucoma and corneal endothelial dysfunction: a case report and literature review. BMC Ophthalmol. 2015 Jan;15(1):3-3.

22 Johnson VP, Grayson M, Christian JC. Dominant microspherophakia. Arch Ophthalmol. 1971 May;85(5):5347.

Andric Christopher Perez-Ortiz and Claudia Palacio-Pastrana share the authorship of this work 


\section{Case Reports in Ophthalmology}

Case Rep Ophthalmol 2020;11:1-7

DOI: $10.1159 / 000505058$

(c) 2020 The Author(s). Published by S. Karger AG, Basel www.karger.com/cop

Rubalcava-Soberanis et al.: Microspherophakia in a 47, XYY Syndrome Patient: A Case Report

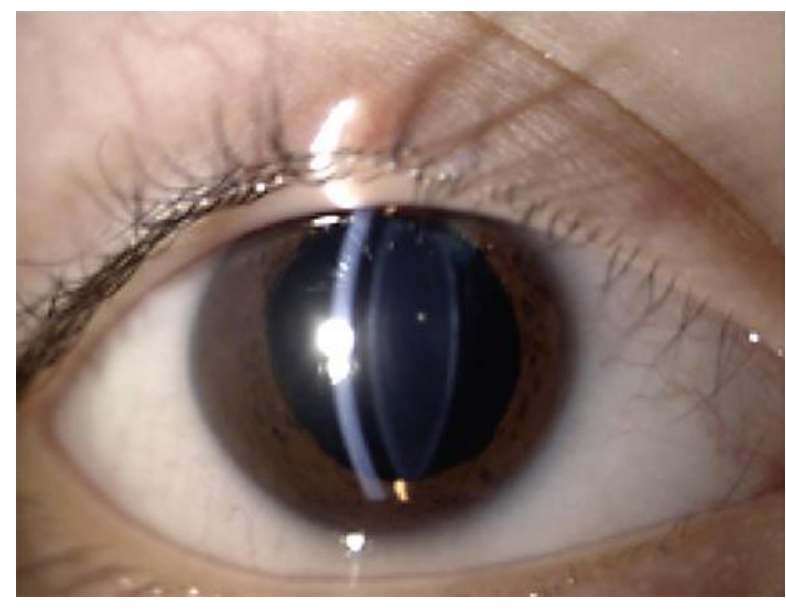

Fig. 1. Optical section of the anterior segment of the right eye. Narrow anterior chamber is evidenced at the expense of the anterior protrusion of a spherical lens.

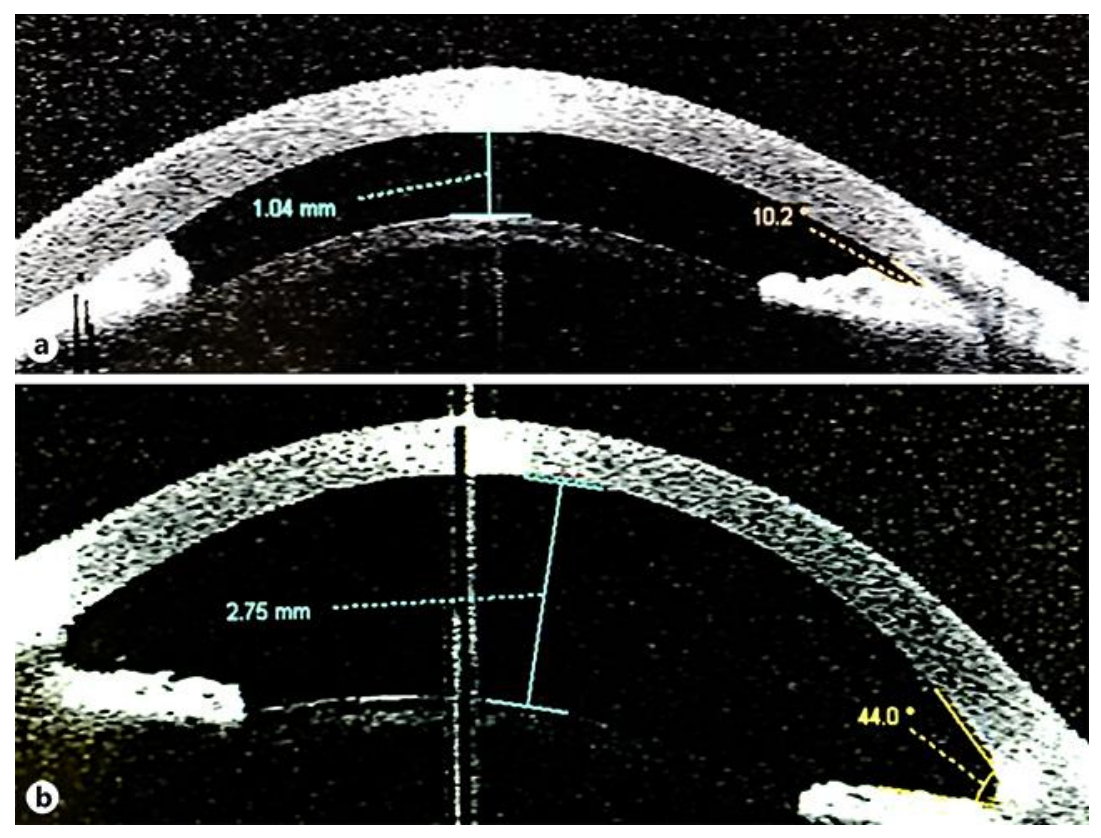

Fig. 2. Anterior segment optical coherence tomography of the OD (a) and OS (b). 
Rubalcava-Soberanis et al.: Microspherophakia in a 47, XYY Syndrome Patient: A Case Report

Table 1. Case reports of ocular involvement in 47, XYY syndrome

First author [Ref.], year

Kitsiou [14], 1986

Kremer [15], 1990

Chew [16], 2009

Medina-Andrad [17], 2018
Ocular involvement

Colobomata of iris and myopia

Multiple retinal atrophic holes located in the posterior pole

Morning glory syndrome (optic nerve enlargement)

Congenital cataract and myopia 